CZASOPISMO INŻYNIERII LA¿OWEJ, ŚRODOWISKA I ARCHITEKTURY JOURNAL OF CIVIL ENGINEERING, ENVIRONMENT AND ARCHITECTURE

JCEEA, t. XXXIII, z. 63 (1/II/16), styczeń-marzec 2016, s. 217-224

\author{
Mariusz JACZEWSKI ${ }^{1}$ \\ Józef JUDYCKI ${ }^{2}$ \\ Piotr JASKUŁA ${ }^{3}$
}

\title{
WŁAŚCIWOŚCI NISKOTEMPERATUROWE BETONÓW ASFALTOWYCH O WYSOKIM MODULE SZTYWNOŚCI (AC-WMS) W BADANIACH TRZYPUNKTOWEGO ZGINANIA
}

\begin{abstract}
Artykuł przedstawia właściwości niskotemperaturowe betonów asfaltowych o wysokim module sztywności. Przedstawione wyniki zostały uzyskane w dwóch badaniach zginania trzypunktowego próbek belkowych: ze stałą prędkością przemieszczenia oraz pod stałym obciążeniem. Obie te metody są od dawna stosowane na Politechnice Gdańskiej do oceny właściwości niskotemperaturowych betonów asfaltowych. Badaniu poddano pięć betonów asfaltowych - trzy betony asfaltowe o wysokim module sztywności (z asfaltami 20/30, PMB 25/55-60 oraz 20/30 MG) oraz dwa konwencjonalne betony asfaltowe (z asfaltami $35 / 50$ oraz 50/70). W trakcie badań oceniano zarówno cechy mechaniczne (wytrzymałość na rozciąganie przy zginaniu, odkształcenie graniczne) jak i cechy reologiczne (parametry modelu Burgersa) wszystkich betonów asfaltowych. Wyniki obu badań laboratoryjnych wykazały, że stosowanie $\mathrm{w}$ betonach asfaltowych o wysokim module sztywności asfaltów modyfikowanych polimerem SBS lub asfaltów multigrade znacząco poprawia właściwości niskotemperaturowe w stosunku do betonów asfaltowych o wysokim module sztywności z twardym asfaltem drogowym. Zauważalna jest także poprawa właściwości niskotemperaturowych w stosunku do konwencjonalnych betonów asfaltowych, ale wymaga ona potwierdzenia $\mathrm{z}$ badaniami w pełnej skali. W przypadku betonów asfaltowych o wysokim module sztywności $\mathrm{z}$ asfaltem drogowym uzyskano wyniki gorsze $\mathrm{w}$ stosunku do konwencjonalnych betonów asfaltowych. Wyniki przedstawione w niniejszym artykule są częścią programu badawczego realizowanego przez Katedrę Inżynierii Drogowej Politechniki Gdańskiej na zlecenie Generalnej Dyrekcji Dróg Krajowych i Autostrad.
\end{abstract}

Słowa kluczowe: betony asfaltowe o wysokim module sztywności, pełzanie, twarde asfalty, wytrzymałość, parametry modelu Burgersa

\footnotetext{
${ }^{1}$ Autor do korespondencji/corresponding author: Mariusz Jaczewski, Katedra Inżynierii Drogowej, Politechnika Gdańska, Narutowicza 11/12, 80-233 Gdańsk, +58 347-27-82, e-mail: mariusz.jaczewski@wilis.pg.gda.pl

2 Józef Judycki, Katedra Inżynierii Drogowej, Politechnika Gdańska

${ }^{3}$ Piotr Jaskuła, Katedra Inżynierii Drogowej, Politechnika Gdańska
} 


\section{Wprowadzenie}

Stosowanie betonów asfaltowych o wysokim module sztywności w Polsce było jednym z rozwiązań przeciwdziałania nadmiernym deformacjom plastycznym nawierzchni, które występowały powszechnie na przełomie lat 1990/2000. Po okresie pojedynczych prób mieszanki AC WMS zostały one powszechnie wprowadzone do stosowania w latach 2008-2012 na większości budowanych dróg ekspresowych i autostrad. Wątpliwości w sprawie stosowania tego typu mieszanek pojawiły się po zimie 2012 roku, gdy na większości budowanych jeszcze odcinków dróg wystąpiły poprzeczne spękania termiczne.

Technologia betonów asfaltowych o wysokim module sztywności pochodzi z Francji, gdzie jest powszechnie stosowana do podbudów i warstw wiążących od lat 80-tych XX wieku z dość dużym powodzeniem. Charakteryzuje się zwiększoną w stosunku do konwencjonalnych betonów asfaltowych zawartością asfaltu i uziarnieniem zbliżonym do uziarnienia warstw ścieralnych. Dodatkowo, by uzyskać wysoki moduł sztywności w mieszankach tych stosowane są asfalty twarde o penetracji rzędu 10-25 jednostek. O ile w polskiej modyfikacji betonów asfaltowych o wysokim module sztywności zastosowano asfalty bardziej miękkie (penetracja 20-30 jednostek), a także ograniczono moduł sztywności, to nadal pozostaje pytanie o ryzyko powstania spękań termicznych nawierzchni. Niniejszy artykuł przedstawia wyniki dwóch badań laboratoryjnych wykonywanych w ramach pracy badawczej dotyczącej możliwości stosowania betonów asfaltowych o wysokim module sztywności w Polsce wykonanej przez Katedrę Inżynierii Drogowej Politechniki Gdańskiej na zlecenie Generalnej Dyrekcji Dróg krajowych i Autostrad [4]. Są także elementem pracy doktorskiej autora [1].

\section{Badane materiały}

Badaniu poddano pięć mieszanek mineralno-asfaltowych do warstwy wiążącej: trzy betony asfaltowe o wysokim module sztywności (z asfaltem zwykłym 20/30, modyfikowanym 25/55-60 oraz multigrade 20/30) oraz dwa konwencjonalne betony asfaltowe ( $\mathrm{z}$ asfaltami zwykłymi $35 / 50$ oraz 50/70). Wszystkie badane mieszanki miały uziarnienie do $16 \mathrm{~mm}$. Mieszanki zostały zaprojektowane w oparciu o wymagania techniczne WT-2 z roku 2010. Szczegółowe informacje dotyczące badanych mieszanek mineralno-asfaltowych przedstawiono $\mathrm{w}[1]$ oraz [5].

\section{Metody badań}

Do oceny właściwości niskotemperaturowych wykorzystano dwa badania zginania belek w schemacie trzypunktowym. Oba testy różniły się tylko sposobem obciążenia: w pierwszym przypadku obciążenie przykładano poprzez stałą prędkość przesuwania się tłoka obciążającego próbkę belkową (stała prędkość 
wynosząca $1,25 \mathrm{~mm} / \mathrm{min}$ ); w drugim przypadku przykładano stałe obciążenie o wartości około $30 \%$ wytrzymałości na rozciąganie przy zginaniu. Pozostała metodyka wykonywania badań, tj. sposób przygotowania oraz rozmiar próbek, schemat badania oraz sposób pomiaru odkształceń były identyczne. Obie metody zostały opracowane przez Judyckiego [2, 3] i później zmodyfikowane przez Judyckiego, Pszczołę i Jaskułę [4]. Schemat badania przedstawiono na rysunku 1. Szczegółowe informacje dotyczące metodyki badań przedstawione zostały w przywołanych publikacjach oraz raporcie badawczym [5].

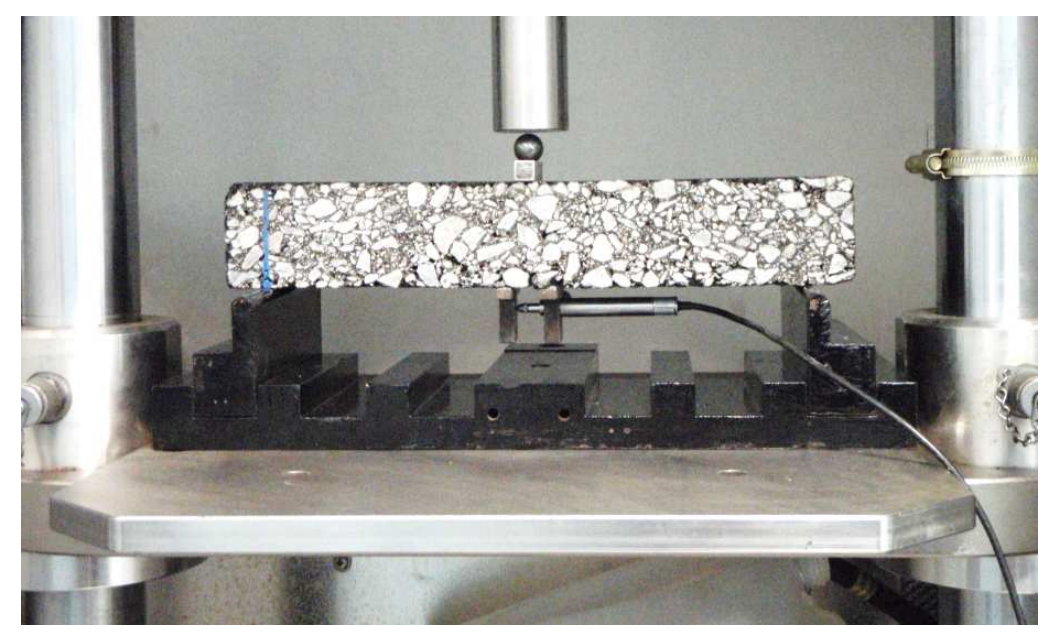

Rys. 1. Próbka belkowa w badaniu zginania pod stałym obciążeniem i zginaniu ze stałą prędkością deformacji

Fig. 1. Beam specimen in bending under constant load test and in bending with constant deformation test

\section{Wyniki}

\subsection{Zginanie ze stałą prędkością deformacji}

W badaniu zginania ze stałą prędkością deformacji badano cechy mechaniczne mieszanek mineralno-asfaltowych $\mathrm{w} 4$ temperaturach: $-30,-20,-10$ oraz $0^{\circ} \mathrm{C}$. Określono dwa parametry: wytrzymałość na rozciąganie przy zginaniu oraz odkształcenie graniczne. Wyniki badań przedstawiono na rysunku 2 (wytrzymałość na rozciąganie przy zginaniu) oraz na rysunku 3 (odkształcenie graniczne). 

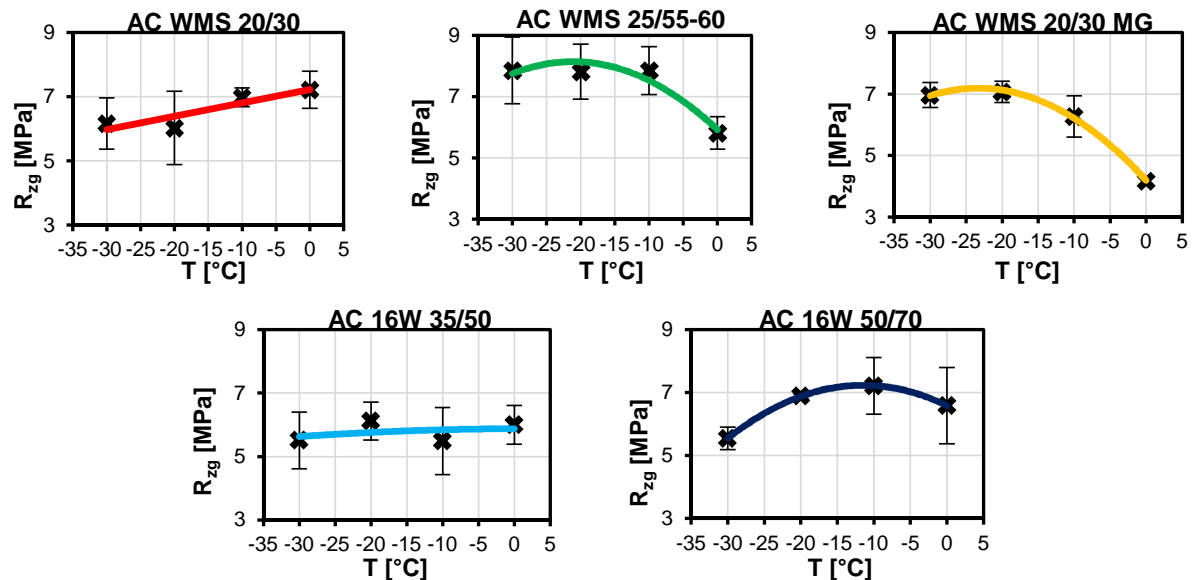

Rys. 2. Wytrzymałość na rozciąganie przy zginaniu badanych mieszanek mineralno-asfaltowych

Fig. 2. Flexural strength of tested asphalt mixtures
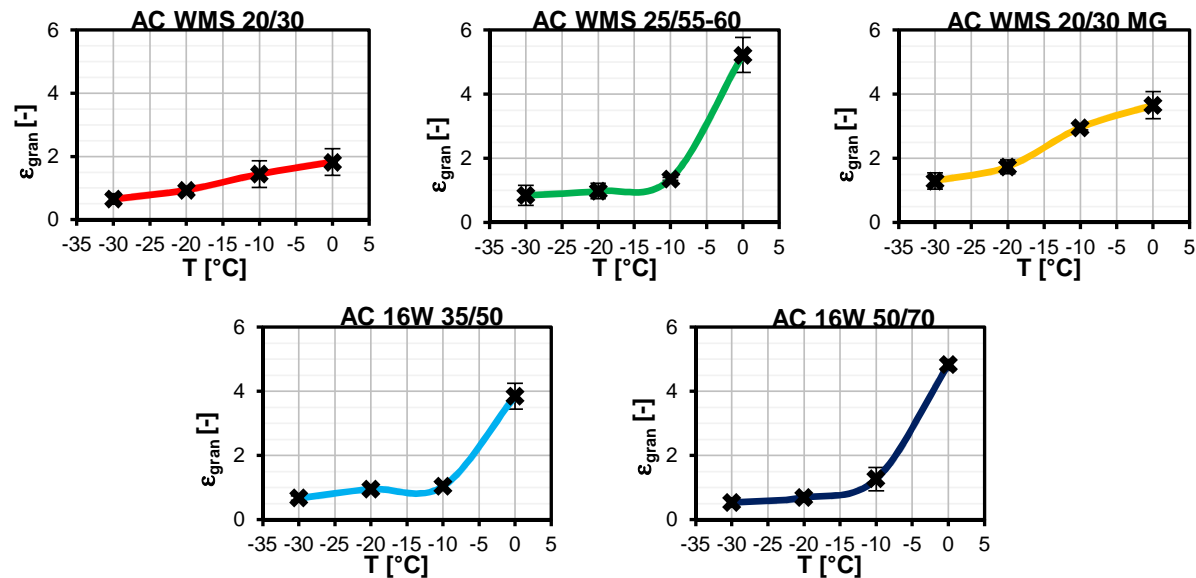

Rys. 3. Odkształcenie graniczne badanych mieszanek mineralno-asfaltowych

Fig. 3. Critical strain of tested asphalt mixtures

\subsection{Zginanie pod stałym obciążeniem}

W badaniu zginania pod stałym obciążeniem wyznaczono dwie charakterystyki betonów asfaltowych: krzywe wiodące (tzw. master curve - opisane szczegółowo w [1] i [5]) oraz parametry reologiczne modelu Burgersa dla temperatur $0,-10$ oraz $-20^{\circ} \mathrm{C}$. Równanie stanu modelu Burgersa pod obciążeniem danej jest wzorem: 


$$
\varepsilon(t)=\sigma_{0}\left[\frac{1}{E_{1}}+\frac{t}{\eta_{1}}+\frac{1}{E_{2}}\left(1-e^{\left(\frac{-t \cdot E_{2}}{\eta_{2}}\right)}\right)\right]
$$

gdzie: $\varepsilon(t)$ - odkształcenie od czasu t, $\sigma_{0}$ - przyłożone stałe naprężenie, $E_{1}, E_{2}$, $\eta_{1}, \eta_{2}$ - parametry modelu Burgersa.

Oba sposoby opisu mieszanek mineralno-asfaltowych używane są powszechnie do opisu zachowania się mieszanek mineralno-asfaltowych pod obciążeniem [6]-[9], a także obliczeń naprężeń termicznych indukowanych w warstwach asfaltowych pod wpływem zmian temperatury [5]. Dodatkowo dla każdej z mieszanek wyznaczono czasy relaksacji, które pokazują zdolność danej mieszanki mineralno-asfaltowej do relaksacji naprężeń. Zestawienie parametrów modelu Burgersa przedstawiono w tablicy 1.

Tablica 1. Parametry modelu Burgersa badanych mieszanek mineralno-asfaltowych

Table 1. Burgers model parameters of tested asphalt mixtures

\begin{tabular}{|c|c|c|c|c|c|c|}
\hline \multirow{3}{*}{ Mieszanka } & \multirow{2}{*}{ Temperatura } & \multicolumn{5}{|c|}{ Parametry reologiczne modelu Burgersa } \\
\hline & & $\mathrm{E}_{1}$ & $E_{2}$ & $\eta_{1}$ & $\eta_{2}$ & $\lambda_{1}$ \\
\hline & ${ }^{\circ} \mathrm{C}$ & $\mathrm{MPa}$ & $\mathrm{MPa}$ & $\mathrm{MPa} \cdot \mathrm{s}$ & $\mathrm{MPa} \cdot \mathrm{s}$ & $\mathrm{s}$ \\
\hline \multirow{3}{*}{$\begin{array}{c}\text { AC WMS } \\
20 / 30\end{array}$} & 0 & 11666 & 1811 & $1,93 \times 10^{7}$ & $3,27 \times 10^{5}$ & 1630 \\
\hline & -10 & 16338 & 4437 & $1,29 \times 10^{8}$ & $1,00 \times 10^{6}$ & 8222 \\
\hline & -20 & 20243 & 7950 & $2,61 \times 10^{8}$ & $1,80 \times 10^{6}$ & 12148 \\
\hline \multirow{3}{*}{$\begin{array}{l}\text { AC WMS } \\
25 / 55-60\end{array}$} & 0 & 8107 & 1989 & $4,51 \times 10^{6}$ & $4,34 \times 10^{5}$ & 556 \\
\hline & -10 & 13417 & 4017 & $3,26 \times 10^{7}$ & $7,99 \times 10^{5}$ & 2442 \\
\hline & -20 & 17514 & 4331 & $9,87 \times 10^{7}$ & $8,91 \times 10^{5}$ & 5646 \\
\hline \multirow{3}{*}{$\begin{array}{l}\text { AC WMS } \\
20 / 30 \text { MG }\end{array}$} & 0 & 4966 & 2423 & $3,20 \times 10^{6}$ & $4,44 \times 10^{5}$ & 656 \\
\hline & -10 & 7048 & 5520 & $8,70 \times 10^{6}$ & $1,10 \times 10^{6}$ & 1183 \\
\hline & -20 & 14328 & 7138 & $1,95 \times 10^{8}$ & $1,85 \times 10^{6}$ & 13470 \\
\hline \multirow{3}{*}{$\begin{array}{c}\text { AC } 16 W \\
35 / 50\end{array}$} & 0 & 7891 & 1469 & $5,65 \times 10^{6}$ & $3,26 \times 10^{5}$ & 793 \\
\hline & -10 & 15609 & 3901 & $5,54 \times 10^{7}$ & $7,84 \times 10^{5}$ & 3616 \\
\hline & -20 & 17241 & 4761 & $9,13 \times 10^{7}$ & $9,34 \times 10^{5}$ & 5460 \\
\hline \multirow{3}{*}{$\begin{array}{c}\text { AC 16W } \\
50 / 70\end{array}$} & 0 & 7712 & 2351 & $4,59 \times 10^{6}$ & $6,47 \times 10^{5}$ & 607 \\
\hline & -10 & 14703 & 3453 & $5,03 \times 10^{7}$ & $6,41 \times 10^{5}$ & 3460 \\
\hline & -20 & 18990 & 5152 & $1,31 \times 10^{8}$ & $1,08 \times 10^{6}$ & 6915 \\
\hline
\end{tabular}

\section{Analiza wyników}

W obu badaniach najgorszymi właściwościami niskotemperaturowymi charakteryzuje się beton asfaltowy o wysokim module sztywności z asfaltem drogowym 20/30. O ile charakteryzuje się ona nieznacznie wyższą wytrzymałością na rozciąganie przy zginaniu od konwencjonalnych betonów asfaltowych, to zauważalny na rysunku 2 jest brak wyraźnego maksimum wytrzymałości. Widoczna jest natomiast dość wyraźna tendencja spadkowa wartości wytrzymałości 
wraz ze spadkiem temperatury. Słabe właściwości niskotemperaturowe widoczne są także na rysunku 3, na którym wyniki odkształcenia granicznego dla AC WMS 20/30 odstają od pozostałych mieszanek. O ile w temperaturze $-30^{\circ} \mathrm{C}$ wyniki dla AC WMS 20/30 są zbliżone do pozostałych mieszanek, to widoczna jest bardzo niska wartość odkształcenia granicznego w przypadku temperatury $0^{\circ} \mathrm{C}$. Może to świadczyć o dużo szybszej zmianie stanu materiału z lepkosprężystego na sprężysty, bądź przejście w stan kruchy. Potwierdzenie to znajduje w badaniu zginania pod stałym obciążeniem. Beton asfaltowy o wysokim module sztywności charakteryzuje się najwyższymi wartościami wszystkich parametrów reologicznych, zarówno sztywności, jak i lepkości (patrz tablica 1). Skutkuje to najdłuższymi czasami relaksacji naprężeń $(\lambda)$ w niskich temperaturach, przynajmniej dwukrotnie dłuższymi $\mathrm{w}$ porównaniu do pozostałych badanych mieszanek.

Pozostałe mieszanki, za wyjątkiem mieszanki AC WMS z asfaltem 20/30 multigrade charakteryzują się $\mathrm{w}$ większości przypadków podobnymi właściwościami (z przewagą mieszanki $\mathrm{z}$ asfaltem modyfikowanym polimerem SBS w niektórych aspektach). Dotyczy to zarówno wartości oraz tendencji w odkształceniu granicznym, jak i wartości parametrów modelu Burgersa i czasów relaksacji naprężeń. Jedyny wyjątek stanowi tutaj wytrzymałość na rozciąganie przy zginaniu mieszanki AC $16 \mathrm{~W}$ z asfaltem 35/50, w której brak jest wyraźnego maksimum wytrzymałości i zachowuje się ona podobnie jak mieszanka AC WMS z asfaltem 20/30.

Na oddzielną uwagę zasługuje mieszanka AC WMS z asfaltem 20/30 multigrade. Większość wyników badań wskazuje, że mieszanka ta charakteryzuje się najwyższą odpornością na spękania niskotemperaturowe z wszystkich badanych mieszanek: osiąga dość wysokie wartości wytrzymałości na rozciąganie przy zginaniu, maksimum wytrzymałości uzyskane zostało $\mathrm{w}$ temperaturze $20^{\circ} \mathrm{C}$, wartości odkształcenia granicznego wykazują najwyższe wartości spośród wszystkich mieszanek, a także charakteryzują się największą jednorodnością. Także w przypadku większości parametrów reologicznych mieszanka AC WMS 20/30 MG uzyskała najlepsze (najniższe) parametry. Dość niepokojący jest jednak znaczny przyrost wartości lepkości w temperaturze $-20^{\circ} \mathrm{C}$, przez co $\mathrm{w}$ bardzo niskich temperaturach mieszanka ta charakteryzuje się bardzo długim czasem relaksacji naprężeń - na poziomie zbliżonym mieszanki AC WMS z asfaltem drogowym 20/30.

Z przedstawionych wyników wynika, że najlepiej zachowują się mieszanki w których zastosowano albo asfalty modyfikowane albo asfalty multigrade. Przy czym do pełnego obrazu brakuje wyników betonów asfaltowych konwencjonalnych z tego typu asfaltami, przy których można by się spodziewać poprawy właściwości w stosunku do asfaltów zwykłych. 


\section{Wnioski}

Z przeprowadzonych badań wynika, że najlepszymi właściwościami niskotemperaturowymi charakteryzuje się beton asfaltowy o wysokim module sztywności z asfaltem 20/30 multigrade. Uzyskał on najlepsze wyniki w obu przedstawionych badaniach. Najgorszymi właściwościami niskotemperaturowymi charakteryzuje się natomiast beton asfaltowy o wysokim module sztywności z asfaltem drogowym 20/30. Uzyskał on najgorsze wyniki w obu przeprowadzonych badaniach. W przypadku pozostałych mieszanek uzyskano wyniki na zbliżonym poziomie, z nieznaczną przewagą mieszanki z asfaltem modyfikowanym.

Same badania laboratoryjne mogą być jednak niewystarczające do kompleksowej i jednoznacznej oceny odporności poszczególnych mieszanek na spękania niskotemperaturowe. O ile uzyskano informacje o odcinkach dróg wybudowanych z mieszankami AC WMS z asfaltem drogowym 20/30 oraz modyfikowanym 25/55-60, to nie wybudowano żadnego odcinka $\mathrm{z}$ mieszanką $\mathrm{AC}$ WMS16 z asfaltem 20/30 multigrade. Jest to szczególnie ważna informacja, gdyż w publikacjach [1], [5] zauważono, że na odcinkach z mieszankami AC WMS spękania termiczne występują dużo częściej niż w przypadku odcinków z konwencjonalnymi betonami asfaltowymi i to niezależnie od rodzaju zastosowanego asfaltu. Dodatkowo badania prowadzone przez Zhao i Hespa [10] wskazują, że technologia stosowana przy produkcji asfaltów multigrade może istotnie zwiększać intensywność spękań termicznych w przypadku rzeczywistych odcinków drogowych. Niemniej jednak, obiecujące wyniki uzyskane w badaniach laboratoryjnych skłaniają do sprawdzenia tego rodzaju mieszanek w rzeczywistych warunkach w pełnej skali.

\section{Literatura}

[1] Jaczewski M.: Wpływ zastosowania betonu asfaltowego o wysokim module sztywności na spękania niskotemperaturowe nawierzchni, praca doktorska, Gdańsk, 2016 (maszynopis po dwóch recenzjach, promotor: prof. dr hab. inż. Józef Judycki).

[2] Judycki J., Zależność wytrzymałości betonu asfaltowego poddanego zginaniu od prędkości wywoływanych odkształceń, Budownictwo Lądowe XXVIII, Zeszyty Naukowe Politechniki Gdańskiej, nr. 245, 1976.

[3] Judycki J., Analiza niektórych właściwości reologicznych drogowego betonu asfaltowego poddanego działaniu obciążeń statycznych, praca doktorska, Gdańsk, 1975.

[4] Judycki J., Pszczoła M., Jaskuła P., Modyfikacja metody zginania belek z mieszanek mineralno-asfaltowych i ocena ich parametrów reologicznych. VII Międzynarodowa Konferencja, Trwałe i Bezpieczne Nawierzchnie Drogowe", Kielce, 2001, s. 91-100.

[5] Judycki J. i wsp., Badanie wpływu zastosowania warstw betonu asfaltowego o wysokim module sztywności (AC-WMS) w konstrukcjach nawierzchni na spękania niskotemperaturowe i na zmniejszenie powstawania deformacji trwałych, Raport końcowy, Gdańsk, listopad 2014, opracowano na zlecenie GDDKiA. 
[6] Mackiewicz P., Szydło A.: Effect of load repeatability on deformation resistance of bituminous mixtures in creep and rutting tests, Archives of Civil Engineering, vol. 49, nr 1, 2003, s. 35-51.

[7] Mejłun Ł., Judycki J., Dołżycki B.: Analiza lepkosprężysta zachowania się konstrukcji nawierzchni drogowej w zależności od temperatury i warunków obciążenia, Drogownictwo, nr 10, 2015, s. 341-347.

[8] Nagórski R., Wiśniakowski P., Błażejowski K., Nagórska M.: Analiza porównawcza właściwości materiałów Burgersa, Bogusłavskich i Zenera w świetle testów naprężenia 1 odkształcenia w odniesieniu do właściwości mieszanek mineralnoasfaltowych, Drogi i Mosty, nr 1, 2012, s. 7-34.

[9] Zbiciak A., Grzesikiewicz W., Wakulicz A.: One-dimensional rheological models of asphalt-aggregate mixtures, Logistyka, $\mathrm{nr}$ 6, 2010.

[10] Zhao M.O., Hesp S.A.M.: Performance Grading of the Lamont, Alberta C-SHRP Pavement Trial Binders, International Journal of Pavement Engineering, vol. 7, nr 3, 2006, s. 199-211.

\section{LOW-TEMPERATURE PROPERTIES OF HIGH MODULUS ASPHALT CONCRETE (AC WMS) IN THREE POINT BENDING TEST}

\section{S u m m a r y}

Article presents low-temperature properties of high modulus asphalt concretes. Presented results were obtained from two bending tests conducted in three point bending scheme: with constant deformation and under constant load. Both methods have been used for assessment of lowtemperature properties in Gdansk University of Technology for a long time. Five different asphalt concretes - three high modulus asphalt concretes (with 20/30 plain, PmB 25/55-60 and 20/30 MG bitumens) and two conventional (with 35/50 and 50/70 plain bitumens) were tested. Both mechanical (flexural strength, critical strain) and rheological (Burgers model parameters) were determined. Results of both tests showed, that using SBS polymer modified or multigrade bitumens significantly improves low-temperature properties of high modulus asphalt concrete in comparison to typical hard grade bitumen. Improvement of low-temperature properties is also visible in comparison to conventional asphalt concretes, but it requires further tests in the field conditions. Asphalt concrete with plain hard grade bitumen showed worse properties in both tests in comparison to conventional asphalt concretes. Presented results are part of the larger research conducted by Department of Highway Engineering of Gdansk University of Technology for General Directorate for National Roads and Motorways.

Keywords: high modulus asphalt concrete, creep, hard grade bitumen, strength

Przestano do redakcji: 07.06.2016 $r$.

Przyjęto do druku: 30.06.2016 r.

DOI: $10.7862 / r b .2016 .78$ 